\title{
Health-related Quality of Life Following Coronary Artery Bypass Graft Surgery in Post-menopausal Women
}

\author{
Kenneth E. Covinsky, MD, MPH ${ }^{7}$, Feng Lin, $M S^{2}$, Vera Bittner, MD, MSPH ${ }^{3}$, Mark A. Hlatky, MD , \\ Sara J. Knight, $P h D^{5}$, and Eric Vittinghoff, $P h D^{2}$ \\ 'Division of Geriatrics, University of California, San Francisco, and San Francisco VA Medical Center (181G), San Francisco, CA, USA; \\ ${ }^{2}$ Department of Epidemiology and Biostatistics, University of California, San Francisco, CA, USA; ${ }^{3}$ Division of Cardiovascular Disease, University \\ of Alabama, Birmingham, AL, USA; ${ }^{4}$ Department of Health Research and Policy and the Department of Medicine, Stanford University School \\ of Medicine, Stanford, CA, USA; 5 Departments of Psychiatry and Urology, University of California, San Francisco, and San Francisco VA \\ Medical Center, San Francisco, CA, USA.
}

OBJECTIVES: To describe the impact of coronary artery bypass graft (CABG) surgery on health related quality of life (HRQOL) in post-menopausal women.

DESIGN: Prospective cohort study.

SETTING: Women enrolled in the Heart and Estrogen/ progestin Replacement Study (HERS).

PARTICIPANTS: One hundred and thirty-seven women (mean age 66.6) who had CABG surgery while enrolled in HERS.

MEASUREMENTS: Physical function was assessed using the 12-item Duke Activity Status Index (DASI), energy-fatigue with the four-item RAND scale, and mental health with the RAND mental health inventory each year. We defined baseline HRQOL from the interview that preceded the CABG (mean 4.6 months pre-CABG). To assess post-CABG HRQOL, we used the first interview that was obtained at least 6 months following the CABG (mean 11.5 months post-CABG).

RESULTS: For all three measures of HRQOL, mean scores post-CABG were virtually identical to mean scores pre-CABG (mean pre and post scores were 20.8, 20.4 for physical function, 49.3, 49.2 for energy-fatigue, and 71.9 and 72.3 for mental health). After adjusting for demographic and clinical characteristics and the expected temporal change in HRQOL, differences between pre and post-operative HRQOL remained minimal. However, on an individual patient level, there was significant variability in HRQOL outcomes. For example, while mean physical function scores changed little, 32\% of women were at least moderately better (scores improved by at least 0.5 standard deviations) following surgery, while $26 \%$ were at least moderately worse (scores declined by at least 0.5 standard deviations).

CONCLUSION: Following CABG surgery in postmenopausal women, on average, HRQOL is virtually identical to the pre-operative baseline. However, there is significant variability, as substantial numbers of women are significantly better or significantly worse.

Received November 16, 2007

Revised April 16, 2008

Accepted May 20, 2008

Published online June 24, 2008
KEY WORDS: coronary artery bypass graft; health related quality of life; physical function; post-menopausal women.

J Gen Intern Med 23(9):1429-34

DOI: $10.1007 / \mathrm{s} 11606-008-0691-0$

(c) Society of General Internal Medicine 2008

\section{INTRODUCTION}

Quality of life is a key outcome after CABG surgery, and for many patients, maintaining quality of life may be of equal importance to increasing longevity. However, compared with studies examining rates of mortality after CABG surgery, relatively few studies have been done examining the health related quality of life outcomes of CABG surgery. The studies that have been done have several methodological limitations. ${ }^{1-15}$ First, most studies have asked patients to recall their pre-morbid health status following recovery from CABG surgery, or have assessed baseline health status immediately before surgery. The former are susceptible to an optimism bias, because patients after major surgery may have a strong desire to believe that surgery made them better. Studies that identify baseline health status immediately before surgery may be more likely to show favorable outcomes of surgery as CABG surgery is often precipitated by cardiovascular events that may result in temporary declines in health status.

In addition, while CABG surgery is increasingly being performed in older women, few studies have focused on this population. While studies in younger patients suggest that health status improves after CABG surgery, it is difficult to extrapolate from these studies to older women as both age and gender are strong determinants of functional outcomes. ${ }^{16,17}$ For example, advanced age is an extremely strong predictor of worsening disability following acute medical illness. Also, older women have higher rates of functional disability than older men.

An older woman undergoing CABG surgery may reasonably ask, "after I recover from surgery, how will I feel compared with how I felt before?" To address this question, we examined outcomes of women who underwent CABG surgery while enrolled in the HERS study. ${ }^{18-20}$ The HERS cohort provides an excellent opportunity to address this issue, because the cohort is representative of women at highest risk for needing CABG surgery: Post menopausal women with known coronary artery disease. Second, information about multiple measures of HRQOL were obtained yearly, making it possible to obtain detailed data about 
pre and post CABG HRQOL that was not subject to recall bias, and less likely to be influenced by any acute events that led to the CABG. Therefore, we conducted this study with the goal of learning how multiple domains of HRQOL changed approximately one year after CABG surgery when compared to a pre-illness baseline.

\section{METHODS}

\section{Study Design and Subjects}

This was an observational study comparing pre-CABG and postCABG health related quality of life among CABG recipients who were enrolled in the Heart and Estrogen/progestin Replacement study (HERS). ${ }^{18,20}$ HERS was a randomized controlled trial that examined cardiovascular and other health outcomes associated with estrogen and progestin therapy in post-menopausal women who were at high risk for cardiovascular endpoints. Subjects were enrolled between February 1993 and July 1998.

One hundred and ninety-seven subjects had a CABG while enrolled in HERS. However, 15 of these subjects were not eligible for this study because their CABG occurred less than 6 months prior to their final HRQOL interview, making it impossible to assess HRQOL after the surgical recovery period. One subject was not eligible because she died before her final HRQOL interview. Sixteen subjects were not eligible because they did not have a pre-CABG HRQOL interview. Of the 165 eligible subjects, 28 were excluded because they did not complete a follow-up interview about their HRQOL, resulting in a final analytic cohort of 137 women. Some selected analyses compare changes in HRQOL in these 137 women to the 2263 women in HERS who had neither CABG nor percutaneous transluminal coronary angioplasty (PTCA). We excluded the 303 women who had PTCA without CABG.

\section{Measurements}

Reports of CABG surgery were obtained by phone interviews every 4 months and at clinic visits. Reports of various measures of HRQOL were obtained with in-person interviews on enrollment in HERS and every year thereafter.

We defined baseline HRQOL from the interview that preceded the CABG. The time window thus could have ranged from 0 12 months prior to the $\mathrm{CABG}$ (mean $=4.6 \pm 2.9$ months). To assess post-CABG HRQOL, we used the first interview that was obtained at least 6 months following the CABG. The time window for this interview could have ranged from 6-18 months following $\mathrm{CABG}$ (mean $=11.5 \pm 3.5$ months). We excluded interviews in the first 6 months following CABG because the post-operative period following $\mathrm{CABG}$ surgery is often prolonged and we were interested in learning the women's HRQOL after the post-operative recovery period.

We used three measures of HRQOL. Physical function was assessed using the 12 -item Duke Activity Status Index (DASI). ${ }^{21}$ The DASI asked subjects whether or not they are able to complete a series of common activities, ranging from basic self-care activities such as dressing to the ability to participate in strenuous sports. Possible scores range from 0 (worst) to 58.2 (best). Energy fatigue was measured using a four-item RAND scale graded from 0 (worst) to 100 (best). ${ }^{22}$ Mental health was measured with the RAND Mental Health Inventory, a five-item scale that assessed anxiety and depression with scores ranging from 0 (worst) to 100 (best). ${ }^{23,24}$

\section{Analysis}

We used chi-square tests and t-tests to compare the characteristics of women who had CABG surgery with women who did not have surgery and paired t-tests to compare the pre- and postCABG HRQOL scores of women who had CABG surgery. To estimate the average change in HRQOL scores after CABG surgery, adjusted for the change that would have been expected in the absence of CABG, we used linear mixed models for annual HRQOL scores among the 137 women with CABG, plus the 2263 HERS participants who did not undergo CABG or PTCA. This analysis excluded scores obtained less than 6 months after CABG. The baseline trajectory of the mean scores was modeled as a linear split spline with knots at 1,2,3 and 4 years after randomization. Departures from this pattern among women undergoing $\mathrm{CABG}$ were modeled by an abrupt change at the time of surgery, followed by a second linear spline. The adjusted pre-post change in the HRQOL score was estimated by the fitted difference between the baseline and post-CABG trajectories 1 year after $\mathrm{CABG} .{ }^{25}$ This model adjusted for baseline characteristics including age, race, tobacco use, diabetes, hypertension, heart failure, prior MI, and prior revascularization history.

To describe the frequency of clinically important changes in individual women, we converted the pre/post difference for each HRQOL measure into standard deviation units, based on the preCABG score distributions. As recommended by Cohen, we classified differences of at least 0.2 standard deviations as mildly better (or worse), 0.5 standard deviations as moderately better (or worse), and differences of 0.8 standard deviations as markedly better (or worse). ${ }^{26,27}$ Differences of more than 0.5 standard deviations on health status measures are generally viewed as clinically significant. ${ }^{28}$

Finally, we examined whether selected demographic and clinical characteristics identified which women were most likely to improve or worsen. These characteristics included mean age, history of diabetes or MI, frequent or severe angina on the interview preceding $\mathrm{CABG}$ (defined as chest comfort with minimal activity or at least once per week) ${ }^{, 24,29}$ a diagnosis of unstable angina between baseline and CABG, and scores on the baseline physical function, energy-fatigue, and mental health scales above the median. For this analysis, we classified woman as much or moderately better as "better", woman slightly better, unchanged, or slightly worse as "unchanged", and women much or moderately worse as "worse." We used statistical tests for trend to compare the prevalence of each characteristic among women in each outcome category.

\section{RESULTS}

At the time of randomization into the HERS study, the mean age of the 137 women who underwent CABG was $66.6 \pm 6.9$ years (Table 1). CABG occurred a mean of 1.7 years after randomization (mean age at time of $\mathrm{CABG}=68.3$ years). $92 \%$ of the women were white, $13 \%$ were current tobacco users, $34 \%$ had diabetes, $47 \%$ had a prior MI, 53\% had chest discomfort on the interview preceding $\mathrm{CABG}$, and $31 \%$ had unstable angina between the time of randomization and CABG. Table 1 also compares the 137 study subjects to the 2263 participants in HERS who do not have 
Table 1. Characteristics of Women Undergoing Coronary Artery Bypass Surgery Compared with Women Undergoing No Cardiac Procedure

\begin{tabular}{|c|c|c|c|}
\hline Characteristic* $^{*}$ & $\begin{array}{l}\text { CABG } \\
(n=137)\end{array}$ & $\begin{array}{l}\text { No procedure } \\
(n=2263)\end{array}$ & $\begin{array}{l}\text { P-value } \\
\text { (chi-sq or } \\
\text { t-test) }\end{array}$ \\
\hline Age (mean years, SD) & $66.6(6.9)$ & $66.6(6.8)$ & 0.99 \\
\hline White, \% & 92 & 89 & 0.27 \\
\hline Married, \% & 64 & 57 & 0.15 \\
\hline$\geq 12$ years education, $\%$ & 76 & 79 & 0.34 \\
\hline Current tobacco use, \% & 13 & 13 & 0.98 \\
\hline History of diabetes, $\%$ & 34 & 22 & $<.001$ \\
\hline Hypertension, \% & 63 & 58 & 0.29 \\
\hline Prior heart failure & 10 & 13 & 0.39 \\
\hline Prior MI, \% & 47 & 52 & 0.28 \\
\hline Prior revascularization, \% & & & 0.002 \\
\hline None & 39 & 27 & \\
\hline PTCA & 32 & 31 & \\
\hline CABG & 29 & 42 & \\
\hline $\begin{array}{l}\text { Severity of chest } \\
\text { discomfort, } \%\end{array}$ & & & $<.001$ \\
\hline None & 47 & 67 & \\
\hline Atypical (non-exertional) & 20 & 15 & \\
\hline With strenuous activity & 9 & 4 & \\
\hline With moderate activity & 13 & 6 & \\
\hline With minimal activity & 4 & 3 & \\
\hline With any activity/rest & 6 & 3 & \\
\hline $\begin{array}{l}\text { Frequency of chest } \\
\text { discomfort }\end{array}$ & & & $<.001$ \\
\hline Not at all & 48 & 67 & \\
\hline $1-3$ times in past 4 weeks & 24 & 20 & \\
\hline $1-3$ times a week & 14 & 7 & \\
\hline Almost daily & 10 & 3 & \\
\hline $1-3$ times a day & 3 & 1 & \\
\hline 4 or more times a day & 1 & 0 & \\
\hline $\begin{array}{l}\text { History of unstable } \\
\text { angina, } \%\end{array}$ & 31 & 4 & $<.001$ \\
\hline Assigned to HRT, \% & $44 \%$ & $50 \%$ & 0.14 \\
\hline \multicolumn{4}{|l|}{ Baseline HRQOL scores } \\
\hline Physical function & 23.7 & 25.7 & .15 \\
\hline Energy-Fatigue & 51.6 & 56.1 & .008 \\
\hline Mental Health & 72.6 & 76.0 & .02 \\
\hline
\end{tabular}

*No procedure group excluded subjects undergoing PTCA during follow-up ${ }^{*}$ Characteristics of Subjects at time of randomization into HERS study

a CABG or PTCA after entry into HERS. Women who had CABG were more likely to have diabetes or chest discomfort, but less likely to have had a prior revascularization procedure. They also had lower baseline energy-fatigue and mental health scores.

For all three HRQOL measures (physical function, energyfatigue, mental health) mean scores before CABG (mean, 4.6 months prior) were virtually identical to mean scores after CABG (mean 11.5 months after). (Table 2). When adjusting for baseline characteristics and the temporal change expected over 1 year, mean scores one year after CABG were virtually identical to scores before the CABG.
However, as shown in Table 3, the similar pre and post CABG mean scores obscure the finding that large and roughly equivalent numbers of women experienced substantial improvements or declines in HRQOL. For example, following CABG surgery, $32 \%$ of women had moderately or much better physical function while $26 \%$ were moderately or much worse. For energy-fatigue, $31 \%$ were at least moderately better while $30 \%$ were at least moderately worse. For mental health, 19\% were at least moderately better, while $14 \%$ were at least moderately worse. As shown in Table 4, subjects with better baseline HRQOL were more likely to further improve following $\mathrm{CABG}$.

\section{DISCUSSION}

We compared the pre and post procedure HRQOL of 137 post menopausal women who underwent CABG surgery. We found that for each measure of HRQOL (physical function, energyfatigue, and mental health), the mean quality of life of women about 1 year after surgery was virtually identical to the mean quality of life before surgery. However, there was substantial inter-individual variability in each HRQOL outcome. For example, while mean physical function scores changed little, $32 \%$ of women were at least moderately better following surgery, while $26 \%$ were at least moderately worse. Thus, if a post-menopausal woman considering CABG surgery asks, "How will I feel after surgery compared with the way I felt before?" Our results suggest the following somewhat unsatisfying answer: "On average, a woman who has the surgery will feel almost exactly the same one year after surgery than in the months preceding surgery. However, many women will feel differently than this average, with around one fourth of women feeling considerably better and one fourth feeling considerably worse."

An important strength of our study was that information about HRQOL was obtained independent of the CABG surgery. This reduces the chance for an optimism bias since women in the study did not know the HRQOL data they were providing would specifically be used to assess the outcomes of their CABG surgery. Furthermore, on average, pre-surgical HRQOL data were obtained 5 months prior to surgery. In contrast, virtually all prior studies either asked women to recall their pre-CABG HRQOL after surgery, or obtained HRQOL information immediately before surgery. Studies based on recall of preoperative HRQOL are susceptible to biases, including a desire of patients to believe they have benefited from surgery. Studies in which HRQOL was obtained immediately before surgery are less susceptible to bias, but address a different clinical question than the question addressed in this study because HRQOL immediately before surgery is likely to be influenced by the acute events that often precipitate surgery and the anxiety that is often present before CABG surgery. To the extent that the goal of

Table 2. Changes in Health Related Quality of Life Measures in Women Having CABG

\begin{tabular}{lllll}
\hline \hline Measure* $^{*}$ & Possible range & $\begin{array}{l}\text { Mean pre-CABG } \\
\text { score** }(\text { std) }\end{array}$ & $\begin{array}{l}\text { Mean post-CABG } \\
\text { score }\end{array}$ & $\begin{array}{c}\text { Difference, 95\% Cl } \\
\text { Difference adjusted for temporal } \\
\text { trend and baseline characteristics }\end{array}$ \\
\hline Physical function & $0-58.2$ & $20.8(13.1)$ & 20.4 & $-0.4(-2.2,+1.5)$ \\
Energy-fatigue & $0-100$ & $49.3(20.7)$ & 49.2 & $-0.1(-3.1,+2.8)$ \\
Mental health & $0-100$ & $71.9(20.7)$ & 72.3 & $-0.6(-4.4,+3.2)$ \\
\hline
\end{tabular}

*Higher scores indicated better health

** Pre-CABG scores were obtained from the HRQOL interview most closely preceding the CABG (mean = 4.6 months)

*** Post CABG scores were obtained from the first HRQOL interview at least 6 months after the CABG (window, $6-18$ months, mean=11.5 months) 
Table 3. Patient Level Changes in Health-related Quality of Life Before and After CABG

\begin{tabular}{|c|c|c|c|c|c|c|c|}
\hline \multirow[t]{3}{*}{ Measure } & \multicolumn{7}{|c|}{ Extent of change* } \\
\hline & Much better & Moderately better & Slightly better & Unchanged & Slightly worse & Moderately worse & Much worse \\
\hline & \multicolumn{7}{|l|}{$\mathrm{N}, \%$} \\
\hline Physical function & $29(22 \%)$ & $14(10 \%)$ & 7 (5\%) & 32 (24\%) & $20(15 \%)$ & $8(6 \%)$ & 27 (20\%) \\
\hline Energy-fatigue & $30(22 \%)$ & $13(9 \%)$ & $13(9 \%)$ & $25(18 \%)$ & $15(11 \%)$ & $17(12 \%)$ & $24(18 \%)$ \\
\hline Mental health & $20(15 \%)$ & $5(4 \%)$ & $9(7 \%)$ & 56 (44\%) & $20(16 \%)$ & $2(2 \%)$ & $15(12 \%)$ \\
\hline
\end{tabular}

* Much better/worse represents a change of at 0.8 standard deviations moderately better/worse represents change of between 0.50 and 0.79 standard deviations slightly better/worse represents a change of between 0.20 and 0.49 standard deviations unchanged represents a change of less than 0.20 standard deviations

CABG is to ameliorate these acute changes, the changes in HRQOL from the time immediately preceding surgery may be very relevant to patients. However, many patients may also be interested in knowing how their health status will compare to a premorbid baseline.

The distinction as to whether preoperative HRQOL is measured immediately before CABG or is based on a premorbid baseline probably explains differences between our results and those of most prior studies. While the literature on the effects of CABG on HRQOL is limited, virtually all studies show a favorable impact of CABG surgery. For example, in a study of mostly male Veterans, Rumsfeld found that physical and mental health status improved in the months after CABG. ${ }^{13}$ Similarly, Ayanian found that HRQOL, as measured by instrumental activities of daily living, social activities, mental health, and vitality improved between before surgery and six months after surgery. ${ }^{2}$ Rumsfeld measured HRQOL shortly before CABG while Ayanian asked subjects to recall preoperative HRQOL at the time of the 6 month post-operative assessment. The overall neutral impact we observed probably reflects our use of a measure of pre-morbid HRQOL, rather than HRQOL immediately before surgery. The importance of whether baseline HRQOL is defined as the period immediately preceding surgery or as a pre-morbid baseline will vary in importance depending on the patient's goals and the unknown natural history of HRQOL changes. For some patients, the goal of CABG surgery may be to reverse recent changes in HRQOL, and these patients may consider returning to their premorbid baseline a success. On the other hand, patients who expect to improve beyond their premorbid baseline may be disappointed by such an outcome.

While our results suggest somewhat less favorable HRQOL outcomes of CABG surgery than prior studies, it is perhaps remarkable that a physiologic stressor as marked as CABG surgery does not result in substantial declines in health status in older women. Extensive evidence is emerging that even modest physiologic stressors can precipitate marked functional deterioration in older patients. For example, medical hospitalization precipitates major new functional deficits, including disabilities in activities of daily living in $1 / 3$ of patients over the age of $70 .{ }^{17}$ This occurs even for causes of hospitalization such as pneumonia that would not be expected to precipitate new functional deficits. About $50 \%$ of patients who sustain a hip fracture fail to return to the premorbid level of mobility. ${ }^{16,30}$ Our finding that, on average, women who have CABG surgery return to their premorbid level of HRQOL suggests that the physiologic stress of surgery is at least balanced by the favorable cardiovascular effects of surgery.

Although we found that on average, HRQOL did not improve from a pre-morbid baseline, our results do not necessarily mean that well being does not improve following CABG. Our HRQOL measures were general global measures of well being that may be affected by many diagnoses other than cardiovascular disease. CABG surgery has little impact on many of the comorbid conditions, such as arthritis that are likely to be important con-

Table 4. Predictors of Better, Same, and Worse Quality of Life Outcomes

\begin{tabular}{|c|c|c|c|c|c|c|c|c|c|c|c|c|}
\hline \multirow{4}{*}{ Characteristic } & \multicolumn{12}{|c|}{ Health related quality of life measure* } \\
\hline & \multicolumn{4}{|c|}{ Physical Function } & \multicolumn{4}{|c|}{ Energy fatigue } & \multicolumn{4}{|c|}{ Mental health } \\
\hline & Better & Same & Worse & p-value & Better & Same & Worse & p-value & Better & Same & Worse & p-value \\
\hline & $n=34$ & $n=69$ & $n=34$ & & $n=33$ & $n=67$ & $\mathrm{n}=37$ & & $\mathrm{n}=37$ & $n=63$ & $\mathrm{n}=37$ & \\
\hline Age, mean & 68 & 67 & 65 & .12 & 68 & 67 & 65 & .17 & 68 & 65 & 68 & .97 \\
\hline Diabetes, \% & 27 & 38 & 35 & .45 & 33 & 36 & 32 & .93 & 43 & 30 & 32 & .32 \\
\hline Prior MI, \% & 59 & 48 & 35 & .053 & 42 & 52 & 43 & .98 & 38 & 51 & 51 & .25 \\
\hline $\begin{array}{l}\text { Frequent or severe chest } \\
\text { discomfort, } \%\end{array}$ & 76 & 80 & 76 & .99 & 79 & 79 & 76 & .74 & 84 & 70 & 86 & .78 \\
\hline Unstable angina, $\%$ & 35 & 28 & 32 & .79 & 39 & 30 & 24 & .18 & 22 & 33 & 35 & .21 \\
\hline $\begin{array}{l}\text { Baseline physical function } \\
\text { score above median, \% }\end{array}$ & 73 & 59 & 29 & $<.001$ & 64 & 57 & 46 & .14 & 68 & 70 & 19 & $<.001$ \\
\hline $\begin{array}{l}\text { Baseline energy-fatigue } \\
\text { score above median, \% }\end{array}$ & 82 & 42 & 38 & $<.001$ & 49 & 63 & 32 & .15 & 38 & 64 & 43 & .64 \\
\hline $\begin{array}{l}\text { Baseline mental health } \\
\text { score above median, } \%\end{array}$ & 76 & 55 & 62 & .21 & 76 & 69 & 38 & $<.001$ & 51 & 78 & 46 & .63 \\
\hline
\end{tabular}

For each measure, subjects whose function was classified as unchanged or slightly better/worse were classified as same 
tributors to global quality of life in older women. CABG surgery is less likely to affect global HRQOL in women in whom HRQOL is dominated by noncardiovascular conditions. However these women may still experience significant symptomatic benefit, if their cardiovascular symptoms improve.

Our study has a number of limitations. First, our sample size was modest. This made it difficult to more definitively determine which characteristics identify women likely to have better or worse HRQOL outcomes. While our results suggest that women with better baseline HRQOL are more likely to improve, these findings should be viewed as preliminary because we did not have sufficient sample size to conduct multivariable analyses. Furthermore, our sample size was not sufficient to examine a number of clinical factors that may be associated with HRQOL changes. Based on other studies on the determinants of functional decline in geriatric populations, preoperative factors likely to influence these outcomes include cognitive impairment, the extent of comorbidity, and psychological factors such as depression. ${ }^{16,30-33}$

Second, we had only limited measures about the frequency and severity of angina. Furthermore, these measures were based on questionnaires and not complete clinical assessments. The RITA-1 trial suggested that the preoperative severity of angina was a major indicator of improvement following CABG surgery. ${ }^{34}$ While we did not identify any differences in the impact of CABG in women who did or did not report angina on the interview prior to $\mathrm{CABG}$, the number of women who did not report angina was small. Similarly, we did not have information on the indication for CABG, and do not know what proportion of women presented with acute coronary syndromes versus stable symptoms. The impact of CABG on HRQOL may differ depending on the clinical stability of the patient.

Third, the HERS cohort was selected to include women with a high risk of cardiovascular endpoints potentially limiting the generalizabilty of our findings. In particular, the cohort included a large number of subjects who had prior $\mathrm{CABG}$, and it is possible that findings may have differed in a cohort of women who were exclusively facing their first CABGs. In addition, our analyses adjusted for the expected temporal trends based on HRQOL changes over time in women who did not have CABG while enrolled in HERS. However, many of these women had remote histories of CABG and some of the "expected" HRQOL changes we modeled may have been the lingering effects of remote CABG.

Fourth, we excluded 28 women because they did not complete HRQOL interviews after CABG. If these women had worse HRQOL, their exclusion would have biased our results in favor of better HRQOL outcomes after CABG.

Fifth, since $92 \%$ of subjects were white, it is not known whether our results are generalizable to minority populations.

In conclusion, we found that on average, HRQOL scores one year after CABG surgery are virtually identical to premorbid HRQOL. However, many women are either substantially better or substantially worse. It will be important for future studies to identify patient and care-related factors associated with better and worse HRQOL outcomes.

Acknowledgment: Supported in part by grants from the National Institute on Aging (5 R01 AG023626-03 and 1K24AG029812-01A1). The HERS study was funded by Wyeth Pharmaceuticals. Wyeth Pharmaceuticals was not involved in the plans to use the HERS database to conduct this study, and was not involved in the data analysis, preparation of the manuscript, or decision to publish this manuscript.
Conflict of Interest: Drs. Vittinghoff and Bittner have previously received grant support from Wyeth Pharmaceuticals.

Author Contributions: Covinsky: Study concept and design; analysis and interpretation of data; preparation of manuscript Lin: Analysis and interpretation of data; preparation of manuscript Bittner: Analysis and interpretation of data; preparation of manuscript Hlatkey: Analysis and interpretation of data; preparation of manuscript Knight: Analysis and interpretation of data; preparation of manuscript Vittinghoff: Study concept and design; analysis and interpretation of data; preparation of manuscript

Corresponding Author: Kenneth E. Covinsky, MD, MPH; Division of Geriatrics, University of California, San Francisco, and San Francisco VA Medical Center (181G), 4150 Clement, San Francisco, CA 94121, USA (e-mail: covinsky@medicine.ucsf.edu).

\section{REFERENCES}

1. Five-year clinical and functional outcome comparing bypass surgery and angioplasty in patients with multivessel coronary disease. A multicenter randomized trial. Writing Group for the Bypass Angioplasty Revascularization Investigation (BARI) Investigators. JAMA. 1997;277(9):715-21. Mar 5.

2. Ayanian JZ, Guadagnoli E, Cleary PD. Physical and psychosocial functioning of women and men after coronary artery bypass surgery. JAMA. 1995;274(22)1767-70. Dec 13.

3. Bradshaw PJ, Jamrozik KD, Gilfillan IS, Thompson PL. Asymptomatic long-term survivors of coronary artery bypass surgery enjoy a quality of life equal to the general population. Am Heart J. 2006;151(2)537-44. Feb.

4. Chocron S, Etievent JP, Viel JF, et al. Prospective study of quality of life before and after open heart operations. Ann Thorac Surg. 1996;61(1) 153-7. Jan.

5. Chocron S, Tatou E, Schjoth B, et al. Perceived health status in patients over 70 before and after open-heart operations. Age Ageing. 2000;29(4)32934. Jul.

6. Fruitman DS, MacDougall CE, Ross DB. Cardiac surgery in octogenarians: can elderly patients benefit? Quality of life after cardiac surgery. Ann Thorac Surg. 1999;68(6)2129-35. Dec

7. Hunt JO, Hendrata MV, Myles PS. Quality of life 12 months after coronary artery bypass graft surgery. Heart Lung. 2000;29(6)401-11. NovDec.

8. Krumholz HM, Forman DE, Kuntz RE, Baim DS, Wei JY. Coronary revascularization after myocardial infarction in the very elderly: outcomes and long-term follow-up. Ann Intern Med. 1993;119(11)1084-90. Dec 1.

9. Caine N, Harrison SC, Sharples LD, Wallwork J. Prospective study of quality of life before and after coronary artery bypass grafting. BMJ. 1991;302(6775)511-6. Mar 2.

10. Lindsay GM, Hanlon P, Smith LN, Wheatley DJ. Assessment of changes in general health status using the short-form 36 questionnaire 1 year following coronary artery bypass grafting. Eur $\mathrm{J}$ Cardiothorac Surg. 2000;18(5)557-64. Nov.

11. Panagopoulou E, Montgomery A, Benos A. Quality of life after coronary artery bypass grafting: evaluating the influence of preoperative physical and psychosocial functioning. J Psychosom Res. 2006;60(6)639-44. Jun.

12. Sahar G, Abramov D, Erez E, et al. Outcome and risk factors in octogenarians undergoing open-heart surgery. J Heart Valve Dis. 1999;8 (2) 162-6. Mar.

13. Rumsfeld JS, Magid DJ, O'Brien M, et al. Changes in health-related quality of life following coronary artery bypass graft surgery. Ann Thorac Surg. 2001;72(6)2026-32. Dec.

14. Shapira OM, Kelleher RM, Zelingher J, et al. Prognosis and quality of life after valve surgery in patients older than 75 years. Chest. 1997;112 (4)885-94. Oct.

15. Thornton EW, Groom C, Fabri BM, Fox MA, Hallas C, Jackson M. Quality of life outcomes after coronary artery bypass graft surgery: relationship to neuropsychologic deficit. J Thorac Cardiovasc Surg. 2005;130(4) 1022-7. Oct.

16. Fried LP, Guralnik JM. Disability in older adults: evidence regarding significance, etiology, and risk. J Am Geriatr Soc. 1997;45(1)92-100.

17. Covinsky KE, Palmer RM, Fortinsky RH, et al. Loss of independence in activities of daily living in older adults hospitalized with medical illnesses: increased vulnerability with age. J Am Geriatr Soc. 2003;51(4) 451-8. Apr. 
18. Grady D, Applegate W, Bush T, Furberg C, Riggs B, Hulley SB. Heart and Estrogen/progestin Replacement Study (HERS): design, methods, and baseline characteristics. Control Clin Trials. 1998;19(4)314-35. Aug.

19. Grady D, Herrington D, Bittner V, et al. Cardiovascular disease outcomes during 6.8 years of hormone therapy: Heart and Estrogen/ progestin Replacement Study follow-up (HERS II). JAMA. 2002;288(1) 49-57. Jul 3.

20. Hulley S, Grady D, Bush T, et al. Randomized trial of estrogen plus progestin for secondary prevention of coronary heart disease in postmenopausal women. Heart and Estrogen/progestin Replacement Study (HERS) Research Group. JAMA. 1998;280(7)605-13. Aug 19.

21. Hlatky MA, Boineau RE, Higginbotham MB, et al. A brief selfadministered questionnaire to determine functional capacity (the Duke Activity Status Index). Am J Cardiol. 1989;64(10)651-4. Sep 15.

22. Ware JE Jr, Sherbourne CD. The MOS 36-item short-form health survey (SF-36). I. Conceptual framework and item selection. Med Care. 1992;30 (6)473-83. Jun.

23. Stewart AL, Greenfield S, Hays RD, et al. Functional status and wellbeing of patients with chronic conditions. Results from the Medical Outcomes Study. JAMA. 1989;262(7)907-13. Aug 18.

24. Burnam MA, Wells KB, Leake B, Landsverk J. Development of a brief screening instrument for detecting depressive disorders. Med Care. 1988;26(8)775-89. Aug.

25. Greenland S. Dose-response and trend analysis in epidemiology: alternatives to categorical analysis. Epidemiology. 1995;6(4)356-65. Jul.

26. Cohen J. Statistical Power Analysis for Behavioral Sciences. 2nd ed. Hillsdale, NJ: Lawrence Erlbaum Associates; 1988.
27. Guyatt GH, Osoba D, Wu AW, Wyrwich KW, Norman GR. Methods to explain the clinical significance of health status measures. Mayo Clin Proc. 2002;77(4)371-83. Apr.

28. Sloan JA, Dueck A. Issues for statisticians in conducting analyses and translating results for quality of life end points in clinical trials. $\mathrm{J}$ Biopharm Stat. 2004; 14(1)73-96. Feb.

29. Rose G, McCartney P, Reid DD. Self-administration of a questionnaire on chest pain and intermittent claudication. Br J Prev Soc Med. 1977;31 (1)42-8. Mar.

30. Mossey JM, Knott K, Craik R. The effects of persistent depressive symptoms on hip fracture recovery. J Gerontol. 1990;45(5)M163-8.

31. Sands LP, Yaffe $\mathbf{K}$, Covinsky $\mathbf{K}$, et al. Cognitive screening predicts magnitude of functional recovery from admission to 3 months after discharge in hospitalized elders. J Gerontol A Biol Sci Med Sci. 2003;58 (1)37-45. Jan

32. Mehta KM, Yaffe K, Covinsky KE. Cognitive impairment, depressive symptoms, and functional decline in older people. J Am Geriatr Soc. 2002;50(6) 1045-50. Jun.

33. Covinsky KE, Fortinsky RH, Palmer RM, Kresevic DM, Landefeld CS. Relation between symptoms of depression and health status outcomes in acutely ill hospitalized older persons. Ann Intern Med. 1997;126(6)41725.

34. Pocock SJ, Henderson RA, Seed P, Treasure T, Hampton JR. Quality of life, employment status, and anginal symptoms after coronary angioplasty or bypass surgery. 3-year follow-up in the Randomized Intervention Treatment of Angina (RITA) Trial. Circulation. 1996;94(2) 135-42. Jul 15. 